\title{
Land Use Change Impacts of Biofuels: Near-VAR Evidence from the US
}

Giuseppe Piroli, Pavel Ciaian and d'Artis Kancs

\section{EERI Research Paper Series No 11/2011}

ISSN: 2031-4892

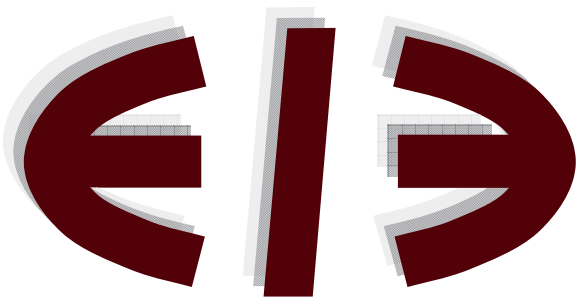

EERI

Economics and Econometrics Research Institute Avenue de Beaulieu 1160 Brussels

Belgium

Tel: +3222988491

Fax: +322 2988490

www.eeri.eu 


\title{
Land Use Change Impacts of Biofuels: Near-VAR Evidence from the US*
}

\author{
Giuseppe Piroli ${ }^{\dagger} \quad$ Pavel Ciaian ${ }^{\ddagger} \quad$ d'Artis Kancs ${ }^{\S}$
}

July 2011

\begin{abstract}
The present paper studies the land use change impacts of fuels and biofuels. We test the theoretical hypothesis, which says that changes in fuel prices cause changes in land use both directly and indirectly and, because of price inter-dependencies, biofuels reinforce the land use change impacts. Our data consists of yearly observations extending from 1950 to 2007 for the US, to which we apply time-series analytical mechanisms of five major traded agricultural commodities, the area of cultivated agricultural land and crude oil price. The empirical findings confirm that markets for crude oil and cultivated agricultural land are interdependent: an increase in oil price by 1 dollar/barrel increases land use between 54 and 68 thousand hectares. We also find that the rise of bioenergy sector accelerates land use change in the US.
\end{abstract}

Keywords: Near-VAR, energy, bioenergy, prices, land use, biofuel support policies.

JEL classification: C14, C22, C51, D58, Q11, Q13, Q42.

${ }^{*}$ The authors acknowledge helpful comments from Cornelis Gardebroek as well as EAAE conference participants in Zürich. Financial support from the FP7 project 'New Issues in Agricultural, Food and Bioenergy Trade' (AgFoodTrade), and the Federal Ministry's of Education projects APVV0706-07, VEGA 10714/09 and KEGA K-08-004-00 is greatly acknowledged. The authors are solely responsible for the content of the paper. The views expressed are purely those of the authors and may not in any circumstances be regarded as stating an official position of the European Commission.

${ }^{\dagger}$ European Commission (DG Joint Research Centre). E-mail: giuseppe.piroli@ec.europa.eu.

${ }^{\ddagger}$ European Commission (DG Joint Research Centre), Slovenská Polnohospodárska Univerzita (SAU), Economics and Econometrics Research Institute (EERI), and Catholic University of Leuven (LICOS). E-mail: pavel.ciaian@ec.europa.eu.

${ }^{\S}$ European Commission (DG Joint Research Centre), Catholic University of Leuven (LICOS), and Economics and Econometrics Research Institute (EERI). E-mail: d'artis.kancs@ec.europa.eu. 


\section{Introduction}

Biofuel production is heavily supported in many countries around the world, particularly in developed economies. The main objectives of biofuel support policies are to reduce the dependence on fossil fuels, to decrease the greenhouse gas emissions, and to ensure a demand for surplus agricultural production (OECD 2008). However, as shown in recent studies of Fischer (2008); Gardebroek (2010); Kancs and Wohlgemuth (2008); Ciaian and Kancs (2011), due to price interdependencies between the energy, bioenergy and agricultural markets, biofuel support policies may have far-reaching side-effects on other markets. For example, they may directly or indirectly increase food prices (e.g. Ciaian and Kancs 2011; Gardebroek 2010), cause negative environmental impacts on farmland cultivated with biofuel crops (Kancs and Wohlgemuth 2008), or induce land use changes (Fischer 2008).

Theoretical models provide two types of explanations for biofuel support policies impact on land use: a direct land use change impact and an indirect land use change impact (Ciaian and Kancs 2011). The direct impact on land use change captures the agricultural land conversion to producing bioenergy crops, i.e. biofuel support policies cause substitution in land use between different types of agricultural crops. The indirect impact on land use change captures expansion in the total agricultural area, implying that new land, which previously was not used for agricultural production (such as idle land, forest land), is converted into farmland.

The empirical literature on land use change impacts of biofuels mostly relies on partial and general equilibrium simulation models (CGE) (e.g. Kancs 2007; Kancs and Wohlgemuth 2008; Hertel Tyner and Birur 2008; OECD 2008; Rosegrant 2008; Searchinger et al 2008; Tyner et al 2010). Searchinger et al (2008) use a worldwide model to analyse the land use change impact of ethanol increase in the US. They estimate that ethanol increase of 56 billion litres brings 10.8 million hectares of additional land into cultivation worldwide: 2.8 million hectares in Brazil, 2.3 million hectares in China and India, and 2.2 million hectares in the US. Their results also show that new crops do not have to necessarily replace all corn diverted to ethanol (12.8 million hectares), because the ethanol by-product replaces roughly one third of animal feed, which otherwise would be diverted away in the absence of feed by-product. Tyner et al (2010) apply the Global Trade Analysis Project (GTAP) model to estimate land use change impact of the US corn ethanol production increase from 6.7 billion litres in 2001 to 56.8 billion litres, as implied by the Energy Independence and Security Act of 2007. According to their study, the estimated land use changes heavily depend on model assumptions, such as yields, population growth and base year. Their simulation results imply that producing 50.0 billion litres of ethanol requires between 1.72 and 2.96 million hectares of additional land, of which between 0.42 and 1.01 million hectares (25\% and 34\%, respectively) occur in the US. In contrast, Darlington (2009) 
finds that the expansion of corn ethanol production to 56.8 billion litres per year by 2015 will unlikely result in conversion of non-agricultural land, arguing that yield improvements will offset the global demand for cropland to meet the corn ethanol production growth.

Most of the simulation studies find that biofuel support policies affect land use positively. However, there is wide variation in the magnitude of the simulated impacts between studies. According to Kancs and Wohlgemuth (2008), an important source of this variation is due to calibrated parameters, particularly those that directly or indirectly affect biofuels, such as price transmission elasticities.

The objective of this paper is to assess the land use change impact of increasing oil prices which, together with bioenergy support policies, make the production of bioenergy more profitable and hence require more farmland. We identify two channels through which changes in oil prices are transmitted to agricultural input and output markets: an indirect input channel and a direct output channel. The indirect input channel affects farm production costs in agriculture, whereas the direct output channel interacts through changes in demand for agricultural commodities (which can also be used for biofuel production). Theoretically, the total effect is ambiguous, because the two channels affect land use in opposite directions. The relative strengths of of the two channels, which depends on the relative importance of energy-based inputs in agricultural production, and on the size of biofuel production, respectively, determines the long-run equilibrium on energy, bioenergy and agricultural markets.

The theoretical model offers testable hypothesis, which says that due to the expansion of biofuel production, the output channel will likely offset the input channel leading to net positive impact on the total agricultural land use, and causing important substitution in land use between different agricultural crops. This may be particular the case of the last 15 years, when the US production of ethanol increased continuously 1100 million gallons in 1996 to 6500 million gallons in 2007 (RFA 2012).

Empirically, we estimate the net effect (direct output net of indirect input channel) of changes in oil prices on agricultural land use, because the two effects cannot be identified separately. Our estimation approach is based on the near Vector Auto Regression (VAR) model. The main advantage of the near VAR approach is that it allows to control for structural effects, such as GDP, yield, consumption, production, that may impact land use changes. To examine the role of biofuels, we take into account structural breaks for the period of biofuel expansion. From the obtained estimates we calculate long-run land use change elasticities. The estimated elasticities of land use change reveal the interdependencies between energy, bioenergy and agricultural markets. These results have high policy relevance, because knowing the potential impact of macroeconomic and policy shocks on all inter-dependent markets allows to increase policy efficiency, and to avoid negative/offsetting side effects. 


\section{Theoretical framework}

\subsection{The model ${ }^{1}$}

Building on theoretical insights of Gardner (2007); de Gorter and Just (2008, 2009); Ciaian and Kancs (2011), we develop a stylised theoretical model in order to identify the channels transmitting price signals between energy, bioenergy and agricultural markets. While acknowledging that the energy, bioenergy and agricultural markets are affected by a multitude of other factors in reality, developing a theoretical model with all the linkages would unnecessary increase the complexity of the analysis, without adding significant insights for identifying the key linkages between the energy, bioenergy and agricultural markets. ${ }^{2}$ Compared to theoretical models in the literature, the main advantage of our approach is that it explicitly models the agricultural sector and explicitly identifies the key transmission channels between the energy, bioenergy and agricultural markets: a direct output channel and an indirect input channel.

Following Ciaian and Kancs (2011), we model five mutually interdependent foodenergy markets: agricultural, biofuel, fossil fuel, by-product, and input. The representative farm can substitute its outputs between biomass and food, according to a constant returns to scale production function of two substitutable inputs: fuel and other inputs (referred to as 'land'). Biomass output is supplied to food and biofuel markets, whereas food commodity is supplied solely to the food market. Biofuel sector produces biofuels and by-product from biomass. The aggregate fuel supply is a sum of biofuel and fossil fuel.

Price signals between the fuel and the agricultural markets are transmitted through two channels: an indirect input channel and a direct biofuel channel. The indirect input channel affects farm production costs on the agricultural market, whereas the direct biofuel channel interacts through biofuels' demand for agricultural commodities on the agricultural markets.

\subsection{Total land use change}

Fuel price affects agricultural production costs and hence the profitability of land through the indirect input channel by causing, for example, a decrease in land demand as a result of an increase in fuel price. Second, the direct biofuel channel has the opposite (increasing) effect on the total land demand. Higher fuel price stimulates biofuel demand, leading to an upward adjustment of agricultural prices, thus improving land profitability. Higher agricultural land demand stimulates conversion of idle and forest land into agricultural land.

\footnotetext{
${ }^{1}$ See Appendix for formal description of the model.

${ }^{2}$ However, all relevant covariates, such as macroeconomic development, are introduced in the empirical analysis (e.g. GDP growth, exchange rate, population growth, inflation)
} 
The overall effect depends on the relative strengths of the two channels. If biofuels play an important role in agricultural markets, then the direct output (biofuel) channel will offset the indirect input channel resulting in higher land use. Otherwise, the total land use will decline. In US the output channel will likely be stronger than the input channel, particularly in the period of biofuel production expansion starting from 1996. For example, the ethanol production increased from 1100 million gallons in 1996 to 6500 million gallons in 2007 (RFA 2012). ${ }^{3}$

According to the underlying theoretical framework, the indirect land use change is caused only by the biofuel channel. In the empirical analysis, however, we will be able to estimate only the combined (total) impact of both channels on the indirect land use change, because the observed indirect land use change is a result of the total land use response net of the land use change caused by the input cost adjustments (indirect input channel). Hence, our estimates will represent a lower bound of the impact of biofuels on land use. As noted above, in order to account for the expansion of biofuels after 1996, we include a dummy variable controlling for structural break in the data series.

\subsection{Land use substitution between commodities}

As a result of biofuel expansion, land substitution between commodities may take place. The indirect input channel has the same impact on both biomass and food commodities. An increase in fuel price causes higher production costs, leading to lower land cultivation of both commodities. The exact impact depends on the relative fuel intensity of agricultural commodities. With fuel price increase, the fuel intensive commodities will reduce land demand relatively more than the fuel extensive commodities.

The direct biofuel channel will affect biomass and food commodities differently. The demand for biomass in the biofuel production due to higher fuel prices will stimulate land cultivation. On the other hand, the food commodity's land demand will decline due to rising biofuel price, as farmers will substitute production to more profitable biomass. Depending on output substitutability and input energy's intensity, the overall effect will be different for the two types of commodities. For biomass, the land use change depends on the relative strengths of the two channels (the same effect as in the case of indirect land use change). For the food commodity, both channels have the same direction, land use decreases in fuel prices.

\footnotetext{
${ }^{3}$ Biodiesel production is considerably less important, consisting only of a small share in the total biofuel production in US.
} 


\section{Empirical implementation}

\subsection{Econometric specification}

Theoretical findings from the previous section suggest that energy, bioenergy and agricultural markets are interdependent. Energy affects agricultural markets through altering agricultural production costs, and through biomass demand for biofuel production. Reversely, agricultural markets impact energy markets through agricultural fuel demand and biofuel supply on the fuel market (Ciaian and Kancs 2011). In order to account for the induced effects on land use changes, the econometric approach needs to account for linkages between all the relevant markets.

In standard regression models by placing particular variables on the right hand side, the endogeneity of all variables sharply violates the exogeneity assumption of a regression equation (Kielyte 2008). Besides the energy-bioenergy-agricultural market interdependencies shown in the theoretical model, one needs to control for other factors that may affect the three markets and linkages between them. The agricultural and energy markets depend on macroeconomic developments, such as GDP growth, consumption development, exchange rate, etc. For example, a favourable macroeconomic development may induce adjustments in both energy and agricultural markets through stimulating production and hence causing land use changes and fuel price rise. These structural adjustments may confound the estimations, likely causing upward bias of the estimated land use effects. In order to take into account these factors, we consider a "structural equilibrium framework", by including a number of macroeconomic and policy control variables, such as GDP growth, population, exchange rate, index of share prices, agricultural subsidies, share of agriculture in GDP/value added, oil production and price indices. The inclusion of these structural variables allows us to take into account a number of effects that otherwise would bias the results. Many econometric approaches applied in the literature for biofuel market analysis relay on simple cointegration and autoregressive model (e.g. Ciaian and Kancs 2011) This is an important shortcoming as they do not take into account structural effects which may significantly bias their estimates.

The problem of endogeneity can be circumvented by specifying a Vector Autoregressive (VAR) model on a system of variables, because no such conditional factorisation is made a priori in VAR models. Instead, variables can subsequently be tested for exogeneity, and restricted to be exogenous then. Given these advantages, a general approach in the literature to analyse the causality between variables in the presence of endogenous variables is VAR model (Lütkepohl and Krätzig 2004). VAR is a statistical model used to capture the linear interdependencies among multiple time series, which generalises the univariate autoregression (AR) models. All the variables in a VAR are treated symmetrically, each variable has an equation explaining its evolution based on its own lags and the lags of all the other variables in the 
model. VAR models can be seen as a 'theory-free' approach to estimate economic relationships. Given that in VAR all variables are modelled as endogenous, it serves as an alternative to the "incredible identification restrictions" in standard regression models (Kielyte 2008).

In the present paper we employ a near-VAR model, which provides an extension of the structural VAR approach, as it does not impose the same lag lengths in all the equations of the system. ${ }^{4}$ Compared to the standard VAR, a near-VAR offers the possibility to incorporate economic constraints, which affect the parameter of lagged regressors and, in this way, avoiding double-counting the effect of interaction effects between the variables. This becomes very important if the model relies on data at different levels, for example micro/macro variables, or, as in our case, sectoral and aggregate data (Imai, Gaiha and Thapa 2008). In the context of the present paper, another important advantage of the near-VAR model is that it offers a robust statistical framework with the ability of integrating alternative economic constraints and structural effects that may impact land use change. Important structural effects represent e.g.: (i) inter-sectoral effects as derived in the theoretical section, and (ii) macroeconomic effects on the energy and agricultural markets, as shown for example in Ciaian and Kancs (2011).

In order to estimate the land use change impacts of biofuels, we specify the following near-VAR model:

$$
\begin{aligned}
{\left[\begin{array}{c}
Y_{t} \\
X_{t}^{c} \\
X_{t}^{b} \\
X_{t}^{r} \\
X_{t}^{s} \\
X_{t}^{w}
\end{array}\right]=} & {\left[\begin{array}{cccccc}
A(L) & 0 & 0 & 0 & 0 & 0 \\
B(L) & C(L) & 0 & 0 & 0 & 0 \\
D(L) & 0 & E(L) & 0 & 0 & 0 \\
F(L) & 0 & 0 & G(L) & 0 & 0 \\
H(L) & 0 & 0 & 0 & I(L) & 0 \\
J(L) & 0 & 0 & 0 & 0 & K(L)
\end{array}\right]\left[\begin{array}{c}
Y_{t-1} \\
X_{t-1}^{b} \\
X_{t-1}^{c} \\
X_{t-1}^{r} \\
X_{t-1}^{s} \\
X_{t-1}^{w}
\end{array}\right] } \\
& +\left[\begin{array}{c}
M \\
N \\
O \\
P \\
Q \\
R
\end{array}\right] Z_{t}+\left[\begin{array}{c}
M(L) \\
N(L) \\
O(L) \\
P(L) \\
Q(L) \\
R(L)
\end{array}\right] Z_{t-1}^{y}+S\left[\begin{array}{c}
\varepsilon_{t}^{y} \\
\varepsilon_{t}^{c} \\
\varepsilon_{t}^{b} \\
\varepsilon_{t}^{r} \\
\varepsilon_{t}^{s} \\
\varepsilon_{t}^{w}
\end{array}\right]
\end{aligned}
$$

where set $Z_{t}$ contains exogenous variables, set $Y_{t}$ contains endogenous macroeconomic variables, and set $X_{t}^{i}$ contains sector-specific endogenous variables. All equa-

\footnotetext{
${ }^{4} \mathrm{~A}$ near-VAR is a special case between the VAR models, which allows for linear restrictions in the system of equations. This means that it is possible to have different number of regressors in each equation. Adjusted-VAR, quasi-VAR and restricted-VAR are other terms used by different authors in the literature.
} 
tions include a constant term and, in order to account for adjustments over time, equations in set $Y_{t}$ include also a trend variable and a dummy variable controlling for structural break in the data. The blocks from $A(L)$ to $R(L)$ contain the parameters of the lagged variables that are estimated by the model. For example, variables in set $Y_{t}$ are not affected by lagged variables in set $X_{t}^{i}$, but are affected by their own (and exogenous) variables. The only parameters to be estimated, therefore, are those contained in the block $A(L)$, while the others are bounded to 0 .

Matrix (1) describes a general representation of the underlying structural model. More precisely, long-run relationships between energy, bioenergy and agricultural markets are identified, and macroeconomic variables affecting these markets are determined. The variables included in matrix (1) are detailed in the next section.

\subsection{Data and variable construction}

Our data consists of yearly observations for crude oil, land use for five major traded agricultural commodities (barley, corn, rice, soybeans, wheat), ${ }^{5}$ the total land, and several structural and control variables (e.g. GDP growth, world population, exchange rate, agricultural support). The data covers US agricultural and energy markets for the period 1950-2007. Crude oil prices are represented by historical free market (stripper) prices. In empirical analysis prices are normalised to the year 1982. Also agricultural data, such output prices, land use and subsidies are all collected on yearly basis. Descriptive statistics of key variables and data sources are detailed in Table 2.

In line with the underlying near-VAR model, all variables are regrouped into three sets: exogenous variables, $Z_{t}$, endogenous macroeconomic variables, $Y_{t}$, and sector-specific endogenous variables, $X_{t}^{i}$.

Set $Z_{t}$ contains exogenous variables that control for change in the total world demand and structural characteristics of economic system and the US agricultural policy: share of agricultural value added in GDP, agr_share $e_{t}$, world population, pop $_{t}^{w}$, US dollar exchange rate, exc_mark $k_{t}$, index of US share prices, share_price $t_{t}$, and agricultural subsidies, subsdies:

$$
Z_{t}^{\prime}=\left[\begin{array}{lllll}
a g r \_s h a r e_{t} & \text { pop } & \text { exc_mark } & \text { share_price } & \text { subsdies }_{t}
\end{array}\right]
$$

Set $Y_{t}$ includes agricultural aggregates and macroeconomics variables that, according to the underlying theoretical framework, are endogenous: oil price, oil_ $p_{t}$, oil production, oil_prod ${ }_{t}$, consumer price index, $c p i_{t}$, farm producer price index, farm_p $p_{t}$ GDP growth, and total agricultural land, tot_land:

$$
Y_{t}^{\prime}=\left[\begin{array}{llllll}
o i l \_p & c p i_{t} & f p i_{t} & \text { oil_prod } & \Delta g d p_{t} & \text { tot_land }
\end{array}\right]
$$

\footnotetext{
${ }^{5}$ These commodities represent almost $75 \%$ of the total utilised agricultural area in the US.
} 
Equations in set $Y_{t}^{\prime}$ include also a trend variable and a dummy variable, which controls for structural break in the series. In the empirical analysis estimate four models: a basic model, and three augmented models. The basic model contains only trend variable. To ensure robustness of basic model's results and to take into account structural break due to biofuel expansion in the US, ${ }^{6}$ the three augmented models include also a dummy variable capturing the structural break in 1996, when the biofuel production (ethanol) started to expand in the US (RFA 2012). According to the underlying theoretical model, expansion in biofuel sector would imply an increase in the relative importance of the direct biofuel channel. The first augmented model considers a structural break in 1996. Dummy variable, d_biofuel_1996, takes value 0 in the first period (1950-1995), and value 1 in the second period (1996-2007). According to RFA (2012), ethanol production increased by $27 \%$ in 1998, and $48 \%$ in 2000 relative to 1996. This implies that in the following years the relative importance of the direct biofuel channel might have increased. To ensure the robustness of our results, we estimate two additional augmented models, which include dummy variables, d_biofuel_1998 and d_biofuel_2000, for the years 1998 and 2000.

Finally, set $X_{t}^{i}$ contains variables, which disaggregate the total agricultural sector into sub-sectors. We consider five agricultural (sub-)sectors: corn, wheat, rice, barley and soybeans. For each agricultural sector we include three variables in set $X_{t}^{i}$ : price, land use and yield:

$$
X_{t}^{i^{\prime}}=\left[\begin{array}{lll}
\text { price }_{t}^{i} & \text { land }_{t}^{i} & \text { yield } \\
t
\end{array}\right]
$$

where $i=$ corn, barley, rice, soybeans and wheat.

Total land, tot_land $t_{t}$, commodity-specific land use, land $d_{t}^{i}$, and oil price, oil_ $p_{t}$, are the key variables of our study. They interlink the three related markets: energy, bioenergy and agricultural. According to the underlying theoretical model, the estimated impact of oil prices on land use will be a result of both channels: the direct biofuel and the indirect input channels. If the biofuel channel is stronger than the input channel, then the overall estimated effect on the indirect land use, land $d_{t}^{i}$, will be positive. In the reverse case, the estimated impact will be negative. This implies that in the empirical analysis the biofuel link to the land use can be tested for only indirectly.

The underlying theoretical model also suggests that, when accounting for structural break in biofuel expansion by including a dummy variable, the relative importance of biofuel channel would decline compared to the basic model. In addition to

\footnotetext{
${ }^{6}$ Note that the dummy variable controlling for structural break may control also for other effects besides the biofuel expansion. For example, it may control for the decoupling of agricultural subsidies in US in 1996, or support measures for biofuel production in US (e.g. blender's tax credit and consumption mandate). Under the blender's tax credit, the blender received a subsidy per gallon of biofuel blended with a fossil fuel (i.e., gasoline or diesel). The mandate established that a fixed amount of biofuel be blended with a fossil fuel.
} 
biofuel expansion, the structural dummy variable controls also for other structural effects, such as policy impacts, and thus may reduce the responsiveness of land use to oil prices. For example, if oil price induces a positive indirect land use change in the basic model, then we expect that in the augmented models with dummy variable the overall estimated effect on the indirect land use would be reduced.

The key difference between sets $Y_{t}$ and $X_{t}^{i}$ is that variables of $Y_{t}$ impact variables in set $X_{t}^{i}$ but, according to the underlying theoretical framework, there is no causality in the reverse direction. The causality between the agricultural aggregates and macroeconomic variables is accounted for in set $Y_{t}$. To avoid duplication of the effects, set $X_{t}^{i}$ is assumed not to affect set $Y_{t}$. Implicitly, this setup implies that cross-effects between the five agricultural sectors are captured by variables in set $Y_{t}$. This specification ensures that the specified near-VAR model has sufficient degrees of freedom, while avoiding the duplication of causal effects between variables. In the same time it allows to estimate commodity-specific effects.

\subsection{Market interdependencies}

Next, we analyse the contemporaneous interactions between endogenous variables, for which we set up an identification scheme. Denote $\theta_{t}$ as residuals obtained from the reduced-form estimation which, according to the underlying structural model, are related to the structural shocks:

$$
W \theta_{t}=K \varepsilon_{t}
$$

The underlying theoretical framework suggests the following identification scheme for the impulse response functions: ${ }^{7}$

$$
\left[\begin{array}{ccccccccc}
1 & 0 & 0 & 0 & a_{15} & 0 & 0 & 0 & 0 \\
a_{21} & 1 & 0 & 0 & a_{25} & 0 & 0 & 0 & 0 \\
a_{31} & a_{32} & 1 & 0 & 0 & 0 & 0 & 0 & 0 \\
0 & 0 & 0 & 1 & 0 & 0 & 0 & 0 & 0 \\
0 & 0 & 0 & 0 & 1 & 0 & 0 & 0 & 0 \\
0 & 0 & 0 & 0 & 0 & 1 & 0 & 0 & 0 \\
a_{71}^{i} & a_{72}^{i} & a_{73}^{i} & 0 & 0 & 0 & 1 & 0 & 0 \\
0 & 0 & 0 & 0 & 0 & 0 & 0 & 1 & 0 \\
0 & 0 & 0 & 0 & 0 & 0 & 0 & 0 & 1
\end{array}\right]\left[\begin{array}{l}
\theta_{\text {oil_pt }} \\
\theta_{\text {cpit }} \\
\theta_{\text {fpit }_{t}} \\
\theta_{\text {oil_prod }_{t}} \\
\theta_{\Delta g d p_{t}} \\
\theta_{\text {tot_land }} \\
\theta_{\text {pricet }}^{i} \\
\theta_{\text {land }}^{i} \\
\theta_{\text {yield }}^{i}
\end{array}\right]=\left[\begin{array}{l}
\varepsilon_{\text {oil_pt }} \\
\varepsilon_{\text {cpit }} \\
\varepsilon_{\text {fpit }} \\
\varepsilon_{\text {oil_prodt }} \\
\varepsilon_{\Delta \text { gdpt }} \\
\varepsilon_{\text {tot_land }} \\
\varepsilon_{\text {price }}^{i} \\
\varepsilon_{\text {land }}^{i} \\
\varepsilon_{\text {yield }}^{i}
\end{array}\right]
$$

Matrix (6) represents the identification of contemporaneous relationships between model variables and their responsiveness to exogenous shocks. In line with the un-

\footnotetext{
${ }^{7}$ In our identification strategy, we assume that $\mathrm{K}$ is an identity matrix.
} 
derlying theoretical framework, we assume that prices are more responsive to shocks than other variables. For example, for agricultural production and land use it takes longer time to adjust due to sunk costs, costly adaptation of technology and natural constraints. Imposing these constraints on the relationships between the variables allows for a contemporaneous impact of oil price changes on all other prices. Similarly, cpi and $f p i$ are assumed to affect agricultural prices contemporaneously. ${ }^{8}$ Row seven in matrix (6) can be interpreted as a cost based inflation of each agricultural sector. Further, we assume a contemporaneous oil price (and consumer price index) response to shocks in GDP growth.

\section{Empirical results}

\subsection{Specification tests}

As usual, we start with determining the lag length. Three standard tests are performed to determine the optimal lag length: Akaike Information Criterion, Schwarz Criterion and Hannan-Quinn Criterion. According to all three tests, the optimal lag order is one. Next, we test for the existence of cointegrating vectors. Both the likelihood ratio and the trace tests confirm that our data are co-integrated in levels, which justifies the specified near-VAR model in levels.

\subsection{Indirect land use change impact}

After identification of the structural model, in order to determine whether the specified model is reasonable, we perform innovation accounting. The impulse response functions for the total land use change for the basic model are reported in Figure 1, which shows the innovation (oil price shock of one standard deviation) response (area of total land use change) in a horizon up to 20 years. In other words, we increase oil price, and predict the response of land use change by taking into account the structural relationships between energy, bioenergy and agricultural markets, and by controlling for macroeconomic effects.

The impulse response results suggest important indirect land use changes: the total cultivated area increases significantly in the analysed period as a result of an increase in oil price (Figure 1). The largest impact can be observed 8 years after the oil price shock of one standard deviation (14.46 USD/barrel), when the total agricultural area increases by almost 1 million hectares. In the following years the increase in the cultivated land is slightly lower (778 thousand hectares in 20 years). The small negative decrease in the first year after the oil price shock can be explained by the fact that farmers are not able to expand their crop land area immediately, although higher input costs are effective instantly. As a result, if everything else

\footnotetext{
${ }^{8}$ Consumer price index also affects the producer price index of farm products.
} 
would stay constant, then higher input costs would imply reduction in input use, also land.

Next, we examine whether structural changes, such as the expansion of biofuel incentives and increase in biofuel production, along with other effects, such as the decoupling of agricultural subsidies in 1996, might have affected indirect land use change. As explained in the previous section, to control for structural break in the second half of nineties, in addition to the basic model we also estimate three augmented models, which include a dummy variable (for 1996, 1998 and 2000). We expect that the inclusion of the dummy variable would decelerate the positive effect of oil price on the total cultivated area, because part of the indirect land use change induced by the biofuel channel may be absorbed by the structural dummy variable. The results are reported in Figure 2.

The results suggest that, when controlling for structural break in 1996, the significant increase in the total cultivated area is confirmed, though the magnitude is lower. In the peak (5-6 years after the oil price shock) the increase in the total cultivated area is 813 thousand hectares (Figure 2), which is around 25\% less compared to the basic model (without controlling for structural break) (Figure 1). Also in the following years the response to oil price shock is lower, when accounting for structural break.

As in the basic model, the impact is larger in the medium-run (5-6 years) compared to the long-run (20 years), when the increase in the total cultivated area is 680 thousand hectares (Figure 2). The differences between the medium- and long-run elasticities in the indirect land use change can be explained by the output (price) channel (increase in the bioenergy supply exerts downward pressure on oil price), and input (cost) channel, because farming itself uses crude oil products (e.g. diesel), the price of which would increase due to higher oil prices. ${ }^{9}$

A similar pattern is observed also for the other two augmented models with structural breaks in 1998 and 2000 (see Figures 3 and 4). The indirect land use change is lower compared to the basic model and the augmented model with structural break in 1996. Compared to the basic model, the indirect land use response in the augmented model with structural break in 1998 is lower by $35 \%$ after 10 years and by $56 \%$ after 20 years. In the model with structural break in 2000 the respective differences are by $52 \%$ after 10 years and by $62 \%$ after 20 years.

Generally, these findings are in line with the underlying theoretical model and with our expectations: both the magnitude of increase in the total crop land area, and the responsiveness of the cultivated area to changes in oil price are lower, when

\footnotetext{
${ }^{9}$ The cost effect hypothesis is confirmed by the coefficient of lagged oil price. In the basic model the lagged oil price has a negative direct impact (-0.533) on the total agriculture land, which is likely caused by increasing cost of production. In the augmented model with structural break, the estimated parameter is still negative (-0.519) and statistically significant (p. value 0.004), which reveals the depressing impact on total agricultural land expansion of an increase in oil price.
} 
basing our calculations on the augmented model's elasticity estimates. This can be explained by the fact that in the second period (1996-2007) the size of bioenergy sector was considerably higher than in the first period (1950-1995) which, according to the underlying theoretical framework, would marginally decrease the indirect land use change impact of biofuels.

The magnitude of our indirect land use change estimates are comparable to previous studies (Searchinger et al 2008; Swinton et al 2011; and Tyner et al 2010). Searchinger et al (2008) find an increase in agricultural land use due to biofuels of 2.2 million hectares. Swinton et al (2011), report that the 2006-2009 leap in field crop prices and the attendant $64 \%$ gain in typical profitability led to a $2 \%$ increase in crop planted area. In order to compare our estimates with those of Swinton et al (2011), we need to convert the estimated elasticities and marginal effects into total (cumulative) changes in crop land area. Taking the average cultivated area of 127.09 million hectares as the base, $2 \%$ would imply an increase of 2.54 million hectares. Our results suggest that an increase in oil price by 1 dollar/barrel increases land use between 54 and 68 thousand hectares. Given that between 2006 and 2009 the crude oil price increased by around 50 dollars/barrel, this implies that the cultivated area increased by 2.70-3.40 million hectares, which is slightly higher compared to Searchinger et al (2008) and Swinton et al (2011). However, the results are of the same order of magnitude, which underlines the general finding that the three markets are interlinked and changes in energy/bioenergy markets does affect agricultural markets, e.g. through changes in the demand for agricultural land.

\subsection{Direct land use change impact}

The impulse response functions for the direct land use change of individual agricultural commodities are reported in Figure 5 (basic model). The results suggest that all agricultural commodities' land use is affected by increasing energy prices, including those commodities that are not directly used for bioenergy production (e.g. rice and barley). As expected, the land use of corn increases significantly (233 thousand hectares after 10 years) in response to an increase in oil price by one standard deviation (14.46 USD/barrel), which is due to the fact that corn is the main commodity used for biofuel production in the US. Similarly, also the land use for wheat and barley production increases (130 and 223 thousand hectares, respectively). In contrast, the area of soybean is negatively affected by a positive fuel price shock (-292 thousand hectares) (Figure 5). This could be due to lower importance of soybeans in biofuel production, which is more than offset by the indirect input channel. Additionally, farmers may substitute from non-biofuel crops to biofuel crops (e.g. corn). Further, soybeans represent an important input for animal production and the indirect input channel may impact the land use of soybean also through adjustments of input costs in animal sector. The smallest response in land use change is estimated for rice (-46 
thousand hectares).

These results are in line with the underlying conceptual framework and confirm that, in addition to the indirect land use change impact, also important direct land use changes take place. The results also suggest an important role of biofuels in land use change. Those agricultural commodities, which are used also for the production of bioenergy, e.g. corn and wheat, are more sensitive in terms of changes in the cultivated area, than those commodities, which are not directly used for the production of bioenergy, e.g. rice.

As above, we examine whether structural changes, such as the expansion of biofuel incentives and increase in biofuel production along with decoupling of agricultural subsidies, might have affected indirect land use changes. We employ exactly the same augmented models with dummy variable specification for structural breaks. Commodity-specific results with structural break in 1996 are reported in Figure 6.

The results for the augmented models (controlling for structural break in the series) suggest that the shape of the impulse response function is similar to the basic model but, as above, the magnitude of land use change is lower (except for wheat). For example, the response in land use in the augmented model with structural break in 1996 relative to the basic model is $4 \%$ - 68\% lower (depending on commodity) after 5 years. For wheat, the land response is $80 \%$ higher after 5 years compared to the basic model. This can be explained by the fact that in the second period (1996-2007) the size of bioenergy's production was considerably higher than in the first period (1950-1995) which, according to the underlying theoretical framework, would increase the direct land use change impact of biofuels. As above, most of the commodities show larger response in medium-run (5-6 years), and faster absorption of oil price shock on indirect land use change.

\subsection{Elasticities of land use change impacts}

The estimated near-VAR model allows us to assess the impact of both types of land use change impacts of biofuels: land use change caused by the indirect input channel, and land use change caused by the direct biofuel channel. In addition, the results from the impulse response analysis allow us to calculate medium- and long-run (5, 10 and 20 years) land use change elasticities. The calculated elasticities are reported in Table 2.

The magnitude of the estimated land use change elasticities ranges between -32.5 thousand hectares and 67.7 thousand hectares per 1 dollar/barrel increases in fuel price in the basic model. Wheat, barley and corn have the elasticity between 5.1 and 17.9 thousand hectares per 1 dollar/barrel increases in fuel price. The elasticity of rice and soybean is between -32.5 and -1.4 hectares per 1 dollar/barrel increases in fuel price. The largest effect is estimated for the total land use, which is equal up to 67.7 thousand hectares per 1 dollar/barrel. 
The land use elasticities are lower in the augmented models compared to the basic model. Analogously, the elasticities are lower, the later the structural break is modelled (1996, 1998 and 2000). The only exception is wheat, for which the elasticity increases. The magnitude of the estimated land use change elasticities ranges between -32.6 thousand hectares and 55.2 thousand hectares per 1 dollar/barrel in the augmented models.

From these results we can further imply that biofuels indeed play an important role, i.e. they affect land use, because the land use change impact is larger for food/bioenergy commodities (e.g. corn) than for food only commodities (e.g. rice). At the same time, when controlling for structural break, there is a reduction in the magnitude of elasticities, implying that part of the biofuel effect is absorbed by the structural break dummy. These findings are consistent both with the theoretical hypothesis and with previous studies (Searchinger et al 2008; Swinton et al 2011; and Tyner et al 2010).

\section{Limitations and outline for future research}

The magnitudes of the results reported in Table 2 should be considered cautiously, however, due to several caveats of our model. First, we cannot separately identify the direct and indirect land use change impacts of biofuels. This implies that our empirical estimates represent a lower bound of the indirect biofuel effects. Given that the estimated land use change is net of land use change caused by the fuel cost adjustments (indirect input channel) and, given that we find a substantial response of land use to changes in oil price, the actual size of the indirect land use change impact of biofuels may be even higher in reality than our results suggest. However, Ciaian and Kancs (2011) show that the indirect input channel is small and statistically not significant, implying that the downward bias is likely to be small.

Second, we cannot explicitly estimate the impact of changes in biofuel polices on land use changes. The impact of policy changes is captured only indirectly through the dummy variable, and through changes in biofuel production (and hence in land use) due to changes in fuel prices. In reality, however, fuel price variation may affect biofuels differently under different policy regimes, e.g. tax credit versus mandate (de Gorter and Just 2008). Given that fuel price determines the profitability of biofuels jointly with biofuel polices (e.g. tax credit), the fuel price impact on biofuels may be stronger with than without biofuel support policies. For example, a fuel price increase may not be sufficient to make biofuel production profitable (and hence cause land use changes) in the absence of biofuel support policies. In such a case, the impact of biofuels on land use will also reflect the impact of biofuel support policies. However, if a higher fuel price causes the same change in biofuel production both with and without policies, then the policy effect will not be identified in our near-VAR model. 
In this case we capture only market induced effect of biofuels. Further, some polices may isolate biofuels from the fuel market. For example, with a binding mandate, the biofuel prices tend to be decoupled from the fossil fuel market, implying that biofuels (and hence land use through the direct biofuel channel) does not respond to fuel prices changes. This effect of biofuels is not identified in our estimation, and hence we do not capture this policy effect, as a result of which the induced land use adjustments would further bias our results downward.

In summary, these limitations imply that we may capture the effects of biofuel polices on land use change only partially. Hence, the presented estimates can be considered as a lower bound, whereas the true impact on land use change may be even larger.

A further potential drawback of our analysis is that by focusing on the US we do not account for price and land use effects of biofuels in other regions, such as Latin America, Africa. However, due to significant biofuel production potential in these regions, the land use impact may be even stronger, because of larger non-cultivated farmland reserves. Our findings suggest that this question is a promising area for future research.

\section{Conclusions}

The present paper studies the interdependencies between the energy prices, bioenergy production, and land use changes. Our data cover the US agricultural and energy markets for the period 1950-2007. We apply near-VAR time-series analytical mechanisms to five major traded agricultural commodities (barley, corn, rice, soybeans and wheat), and the total agricultural land, along with weighted crude oil price and structural variables. An important advantage of the employed near-VAR approach is that it allows to set up a structural model and to control for a number of macroeconomic variables, such as such as GDP, yield, consumption, production. Estimating several near-VAR models we indirectly examine the response of land use to changes in oil prices. However, we cannot not separately identify biofuel effects on land use change.

The underlying theoretical model suggests two types of impacts of fuel and biofuel price increase on land use change: a direct land use change impact and an indirect land use change impact. The direct impact on land use change refers to a situation, when the land already used for agriculture is switched to produce biofuel crops, causing substitution in land use between different types of crops. The indirect impact on land use change reflects a case, when the total land cultivation expands, implying that new land, which before was not used for agricultural production (such as idle or forest land), is converted into farmland.

Our empirical findings confirm the theoretical hypothesis that energy prices do 
affect land use in the US. The impulse response analysis results suggest that land of all agricultural commodities is affected by energy prices, including those that are not directly used for bioenergy production. However, the impact on land use change is higher for the food/bioenergy commodities (e.g. corn) than for food only commodities (e.g. rice), suggesting the importance of biofuels in transmitting the fuel price signals to land use changes.

Based on the innovation accounting results, we calculate medium- and long-run land use change elasticities. The magnitude of the long-run price transmission elasticities varies between -32 and 18 thousand hectares for individual crops and between 54 and 68 thousand hectares for the total land per 1 dollar/barrel increases in fuel price, depending on the time horizon considered. When controlling for structural break in biofuel production and public support policies, as expected, long-run price transmission elasticities are lower.

Our findings are highly important for policy makers, as they help to better understand the role of fuel prices, and suggest a potential role of biofuels (and biofuel policies) in determining the induced land use changes. According to our results, biofuels may reinforce both the total agricultural land use change, as well as land substitution among different crops. These results suggest that policies, which stimulate biofuel production (which is the case of many developed countries), may indeed have undesirable environmental consequences and/or adverse climate change impact leading to more carbon emissions due to land use changes induced by the expansion of croplands for biofuel production. These findings contradict some recent statements made by the EU and US policy executives, who attempt to play down the role of bioenergy policy spillovers to agricultural input and output markets.

\section{References}

[1] Ciaian P., and Kancs D. (2011). 'Interdependencies in the Energy-BioenergyFood Price Systems: A Cointegration Analysis.' Resource and Energy Economics 33: $326-348$.

[2] Darlington, T.L. (2009). 'Land Use Effects of U.S. Corn-Based Ethanol.' Air Improvement Resource.

[3] de Gorter, H., and Just, D.R. (2009). "The Economics of a Blend Mandate for Biofuels." American Journal of Agricultural Economics. 91(3): 738-750.

[4] Fischer, G. (2008). Implications for land use change, Paper presented at the Expert Meeting on Global Perspectives on Fuel and Food Security, 18-20 February 2008. Rome, FAO. 
[5] Gardebroek, C. (2010). 'Do Oil Prices Increase Corn Price Volatility?' Paper presented at the IATRC meeting, Berkeley, California. December 12 14, 2010.

[6] Gardner, B., (2007). 'Fuel Ethanol Subsidies and Farm Price Support', Journal of Agricultural \& Food Industrial Organization 5(2): Article 4.

[7] Hertel, T., Tyner, W. and Birur, D. (2008). Biofuels for all? Understanding the Global Impacts of Multinational Mandates. GTAP Working Paper No. 51, Center for Global Trade Analysis, Department of Agricultural Economics, Purdue University.

[8] Imai, K., Gaiha, R., and Thapa, G. (2008). Food and Oil Prices and their Implications for Rural Poverty, Working Paper.

[9] Kancs, D. (2007). 'Applied General Equilibrium Analysis of Renewable Energy Policies', International Journal of Sustainable Energy, 27: 1-20.

[10] Kancs, D., Wohlgemuth, N. (2008). Evaluation of renewable energy policies in an integrated economic-energy-environment model. Forest Policy and Economics, 10: 128-139.

[11] Kielyte J. (2008). Estimating panel data models in the presence of endogeneity and selection. Journal of Economics and Econometrics, 51: 1-19.

[12] Lütkepohl, H. and Krätzig M. (2004). Applied Time Series Econometrics, Cambridge University Press .

[13] OECD (2008). Biofuel support policies: An economic Assessment. Organisation for Economic Co-operation and Development (OECD), Paris.

[14] RFA (2012). 'Statistics - Historic U.S. fuel Ethanol Production.' Renewable Fuels Association, http://www.ethanolrfa.org/pages/statistics

[15] Rosegrant, M. W. (2008). Biofuels and grain prices: Impacts and policy responses. Testimony for the U.S. Senate Committee on Homeland Security and Governmental Affairs, May 7 2008. IFPRI.

[16] Schnepf, R., (2010). Agriculture-Based Biofuels: Overview and Emerging Issues, Congressional Research Service, Washington, D.C.

[17] Searchinger, T., R. Heimlich, R. A. Houghton, F. Dong, A. Elobeid, J. Fabiosa, S. Tokgoz, D. Hayes and T.H. Yu (2008). 'Use of U.S. Croplands for Biofuels Increases Greenhouse Gases Through Emissions from Land Use Change.' Science 319: $1238-1240$. 
[18] Swinton, S. M., B. A. Babcock, L. K. James, and V. Bandaru (2011). 'Higher US crop prices trigger little area expansion so marginal land for biofuel crops is limited', Energy Policy, 39: 5254-58.

[19] Tyner W.E., Taheripour, F., Zhuang, Q., Birur, D. and Baldos, U. (2010). 'Land Use Changes and Consequent CO2 Emissions due to US Corn Ethanol Production: A Comprehensive Analysis.' Final Report Department of Agricultural Economics, Purdue University. 


\section{Appendix: Theoretical model}

The present model builds on Gardner (2007); Gorter and Just (2008, 2009); Ciaian Kancs (2011). We introduce two important extensions. First, we assume two agricultural commodities: one suitable for biofuel production (referred to as "biomass") ${ }^{10}$ and one not suitable for biofuel production (referred to as "food"). Second, we consider the transmission of prices also through the input channel. Both extensions improve the model predictions.

The economy consists of vertically integrated agricultural, biofuel, fossil fuel, byproduct, and input markets (Figure 7). The representative farm can substitute between producing two agricultural commodities (biomass and food) using constant return to scale production functions of two substitutable inputs: fuel and other inputs (referred to as "land"). Agricultural output can be supplied to food market and to biofuel market. We assume fixed Leontief coefficient transformation function of biomass into biofuel and by-product from biofuel production. Further, we assume a downward sloping demand for food and by-product, and an upward sloping supply curve for land. The aggregate fuel supply is a sum of biofuel and fossil fuel supplies. The aggregate fuel demand is a sum of agricultural and non-agricultural fuel demand. The fossil fuel supply (non-agricultural fuel demand) is given by upward (downward) sloping functions of prices.

The representative agricultural farm maximises its profits according to: $\Pi=$ $\sum_{i} p^{i} Q^{i}\left(N^{i}, K^{i}\right)-w N^{i}-r K^{i}$, which implies the following equilibrium conditions:

$$
\begin{aligned}
& p^{i} \frac{\partial Q^{i}}{\partial N^{i}}=w \quad \text { for } i=A B, A N \\
& p^{i} \frac{Q^{i}}{\partial K^{i}}=r \quad \text { for } i=A B, A N
\end{aligned}
$$

where $N$ is non-fuel input (land), $K$ is fuel input, $p$ is farm output price, $w$ is land rental price, and $r$ is fuel price. $A B$ is index for biomass, and $A N$ is index for food commodity. Equations (7) and (8) are marginal conditions for land and fuel input, respectively, and determine input demand and output supply of agricultural commodities.

In Figure 8 the derived supplies of biomass, $S^{A B}$, and food commodity, $S^{A N}$, are shown as upward sloping curves (panels a and d, respectively). ${ }^{11}$ The aggregate world food demand for biomass and food commodity is denoted by $D^{A B}\left(p^{A B}\right)$ and $D^{A N}\left(p^{A N}\right)$, and are shown in panels a and d, respectively. The world supply of land

\footnotetext{
${ }^{10}$ Note that we consider the case where the agricultural commodity suitable for biofuel production may be used for both food and biofuel production. We denote it as biomass to simplify the text.

${ }^{11}$ In Figure 8 we show biomass market (panel a), fuel market (panel b) and food commodity market (panel d) (by-product and land markets are not shown). The effects sown in Figure 8 take into account adjustments in all markets.
} 
is given by $S^{N}(w)$ (not shown).

We assume constant Leontief transformation technology in biofuel sector with constant extraction coefficient denoted by $\beta$. Each unit of biomass results in $\beta$ units of biofuel. ${ }^{12}$ Additionally, biofuel production yields feed by-product, $\gamma$, units quantity per one unit of biomass. To simplify the analyses, we assume constant value of unit processing costs (adjusted for mark-up), $c$, incurred to biofuel production from one unit of biomass. This implies that biofuel supply, $S^{B}(r)$, and by-product supply, $S^{O}\left(p^{O}\right)$, represent the excess supply of biomass, $S^{A B}-D^{A B}$, adjusted by constant extraction coefficients: $S^{B}=\beta\left(S^{A B}-D^{A B}\right)$ and $S^{O}=\gamma\left(S^{A B}-D^{A B}\right)$, respectively, where $p^{O}$ is the price for by-product. In Figure 8 biofuel supply, $S^{B}$, is shown in panel b.

The world supply of fossil fuel together with biofuel supply generates the aggregate fuel supply curve, $S^{T F}(r)=S^{F}+S^{B}$, where $S^{F}(r)$ is the world supply curve of fossil fuel (panel b in Figure 8). The aggregate fuel demand, $D^{T F}(r)$, is a sum of agricultural fuel demand, $K^{A B}+K^{N B}$, and non-agricultural fuel demand, $D^{N F}(r)$ (panel b in Figure 8). In order to simplify the analysis, we assume perfect substitutability between biofuel and fossil fuel in consumption. ${ }^{13}$

The equilibrium conditions for agricultural, input and fuel markets can be summarised in five equilibrium conditions. Food production from biomass with no biofuel production is given by:

$$
\text { if } p_{o}^{A B} \geq \beta r+\gamma p_{o}^{O}-c \Rightarrow S^{B}=S^{O}=0 \Rightarrow D^{A B}=S^{A B}
$$

where $p_{o}^{A B}$ is the equilibrium price for biomass in absence of biofuel production, $p_{o}^{O}$ is by-product price in absence of production of by-product from biomass. Food and biofuel production from biomass is given by:

$$
\begin{array}{cl}
\text { if } \quad p_{o}^{A B}<\beta r+\gamma p^{O}-c \Rightarrow S^{B}>0, S^{O}>0 \Rightarrow S^{A B}-D^{A B}>0 \\
\text { and } p^{A B}=\beta r+\gamma p^{O}-c
\end{array}
$$

Food commodity equilibrium:

$$
S^{A N}=D^{A N}
$$

Land market equilibrium:

\footnotetext{
${ }^{12}$ We assume that this coefficient also adjusts for quality differences between biofuel and fossil fuel. Hence it represents biofuel in equivalent of fossil fuel.

${ }^{13}$ In reality, fuel containing low share of biofuels (e.g. $10 \%$ or less in the case of ethanol) can be used in virtually all standard vehicles. However, fuel with high share of biofuels requires engine adaptation, which implies additional (fixed) costs to consumers. Hence, depending on the relative importance of these adjustment costs, the theoretical model may slightly overstate the impact of biofuels on agricultural prices.
} 


$$
N^{A B}+N^{A N}=S^{N}
$$

By-product market equilibrium:

$$
S^{O}=D^{O}
$$

where $D^{O}\left(p^{O}\right)$ is by-product demand. Fuel market equilibrium:

$$
S^{T F}=D^{T F}
$$

Equation (3) determines the equilibrium condition for biomass. The unit return of biomass, if used to produce biofuels, is given by the adjusted fuel and by-product prices net of processing costs $c: \beta r+\gamma p^{O}-c$. If the return from biofuel is smaller than the biomass equilibrium price in the absence of biofuel production, $p_{o}^{A B}$, then biofuel production is not profitable in equilibrium. In this case the equilibrium biomass price is determined by intersection of biomass demand and supply, $D^{A B}=S^{A B}$ (equation 3a). Biofuel production is in equilibrium, $S^{B}>0$, when the unit return of biomass used for production of biofuels is higher than the biomass price, $p_{o}^{A B}$, on the food market: $\beta r+\gamma p^{O}-c>p_{o}^{A B}$. In this case the equilibrium biomass price is determined by the price for fuel and by-product: $p^{A B}=\beta r+\gamma p^{O}-c$ (equation $3 \mathrm{~b}$ ). Equation (10) represents the equilibrium condition for food commodity. Equations (11) and (12) determine the equilibrium on land and by-product markets, respectively. Equation (13) is clearing condition for the aggregate fuel market equilibrium, where $S^{T F}=S^{F}+S^{B}$ and $D^{T F}=D^{N F}+K^{A B}+K^{A N}$.

Figure 8 shows the equilibrium prices and quantities for biomass market (panel a), fuel market (panel b) and food commodity market (panel d). The equilibrium price and quantity for biomass is $p_{o}^{A B}, Q^{A B}$, and the equilibrium price and quantity for fuel is $r, Q^{F}$. There is no biofuel production in equilibrium, because the return from biomass for biofuel production would be lower than the price obtained if sold on the food market. With fuel price $r$, the unit return of biomass for biofuel production is given by $p^{A B}\left(=\beta r+\gamma p_{o}^{O}-c\right)$, while the equilibrium food price is $p_{o}^{A B}$. As shown in panel a, food price is lower than the equilibrium price for biomass, $p^{A B}<p_{o}^{A B}$, implying no biofuel production in equilibrium. ${ }^{14}$ Finally, the equilibrium price and quantity of food commodity is $p^{A N}, Q^{A N} \cdot{ }^{15}$

\section{Figures and Tables}

\footnotetext{
${ }^{14}$ Note that the fuel price $r_{o}$ is equivalent to return from the biofuel production at price of biomass $p_{o}^{A B}$. Everything else equal, the biofuel production is profitable for fuel prices higher than $r_{o}$.

${ }^{15}$ As noted above, we assume that this commodity is used only for food production.
} 


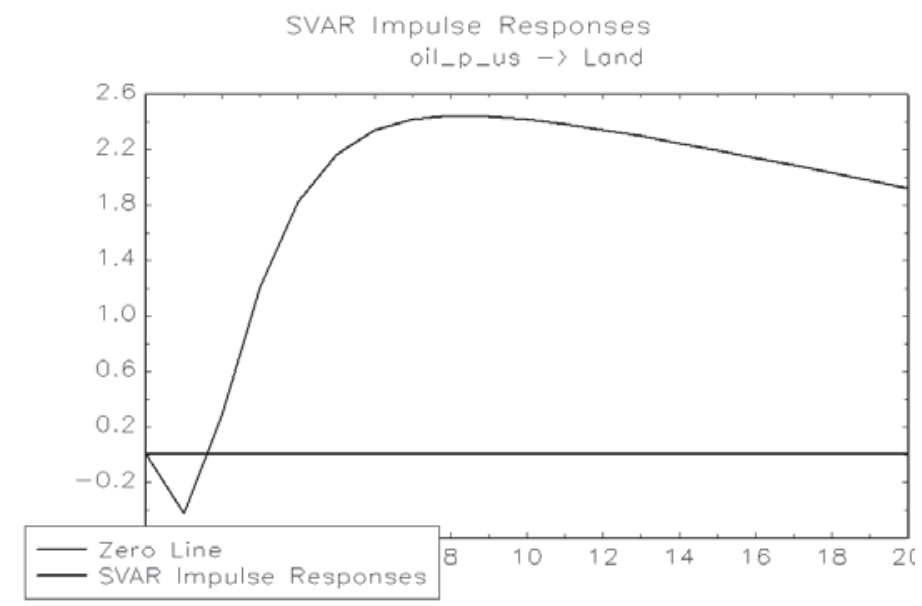

Figure 1: Impulse response function of total land use (basic model). Notes: Y axis: area in million acres; $\mathrm{X}$ axis: years. Impulse: positive oil price shock (1 STD) in USD; response: changes in land use.

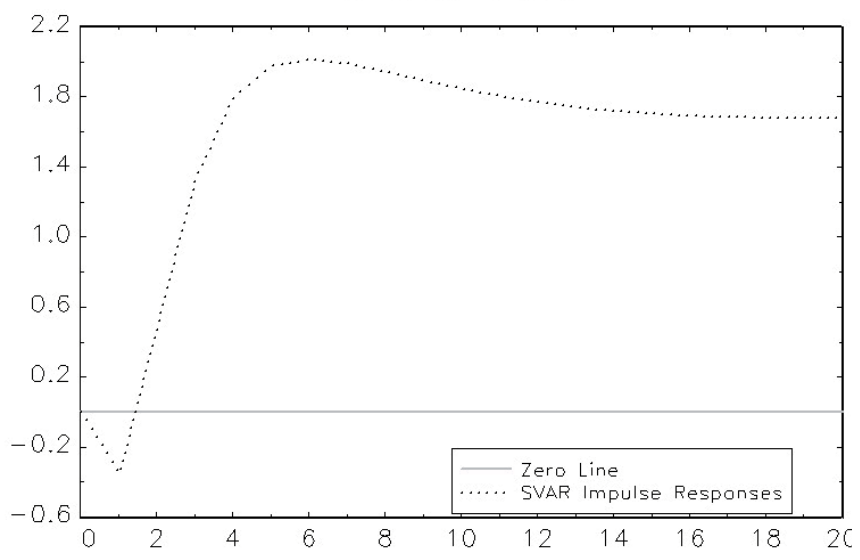

Figure 2: Impulse response function of total land use (controlling for structural break in 1996). Notes: $\mathrm{Y}$ axis: area in million acres; $\mathrm{X}$ axis: years. Impulse: positive oil price shock (1 STD) in USD; response: changes in land use. 


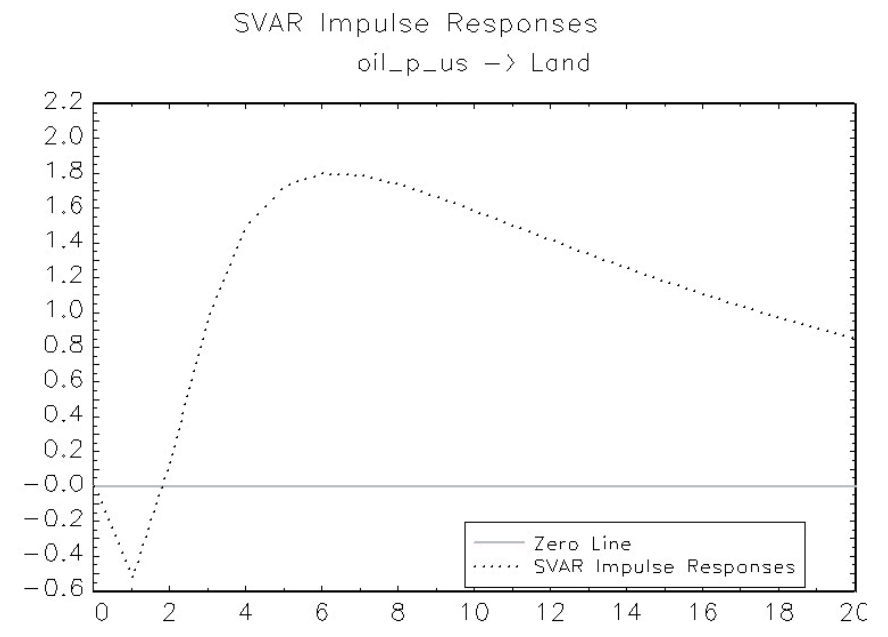

Figure 3: Impulse response function of total land use (controlling for structural break in 1998). Notes: $\mathrm{Y}$ axis: area in million acres; $\mathrm{X}$ axis: years. Impulse: positive oil price shock (1 STD) in USD; response: changes in land use.

SVAR Impulse Responses

oil_p_us $\rightarrow$ Land

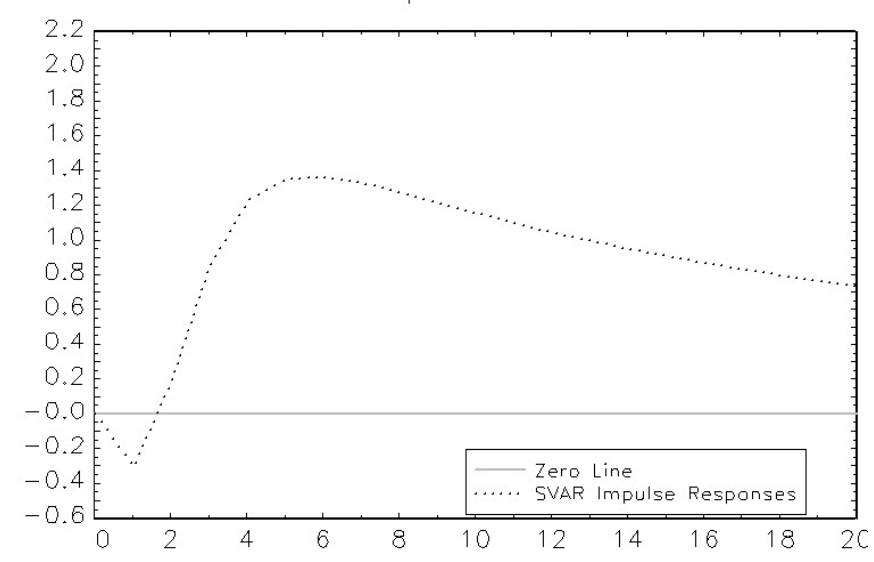

Figure 4: Impulse response function of total land use (controlling for structural break in 2000). Notes: $\mathrm{Y}$ axis: area in million acres; $\mathrm{X}$ axis: years. Impulse: positive oil price shock (1 STD) in USD; response: changes in land use. 


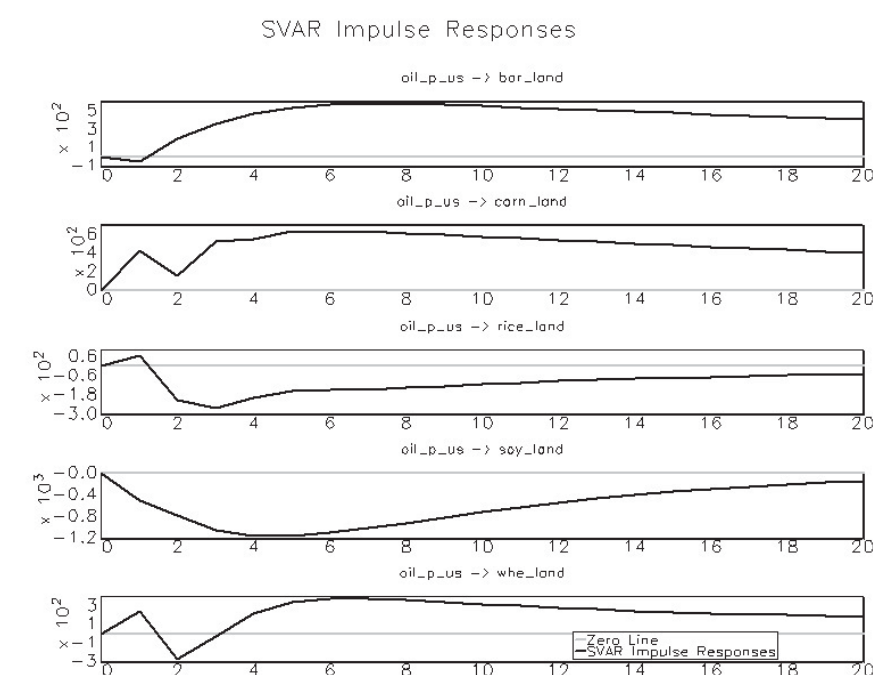

Figure 5: Impulse response functions of direct land use change (basic model). Notes: $\mathrm{Y}$ axis: area in thousand acres; $\mathrm{X}$ axis: years. Impulse: positive oil price shock (1 STD) in USD; response: changes in land use. Commodities from the top: barley, corn, rice, soybeans and wheat.

SVAR Impulse Responses
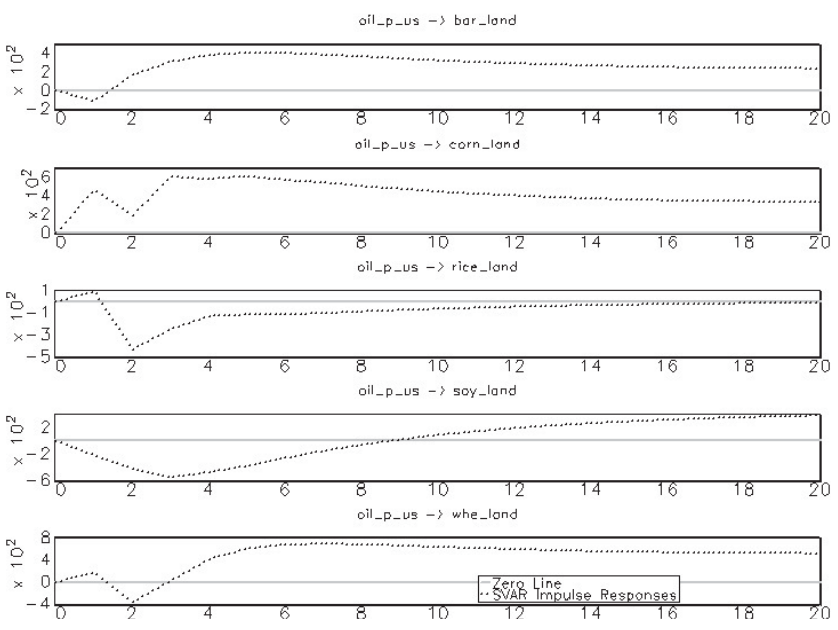

Figure 6: Impulse response functions of direct land use change (controlling for structural break in 1996). Notes: Y axis: area in thousand acres; X axis: years. Impulse: positive oil price shock (1 STD) in USD; response: changes in land use. Commodities from the top: barley, corn, rice, soybeans and wheat. 


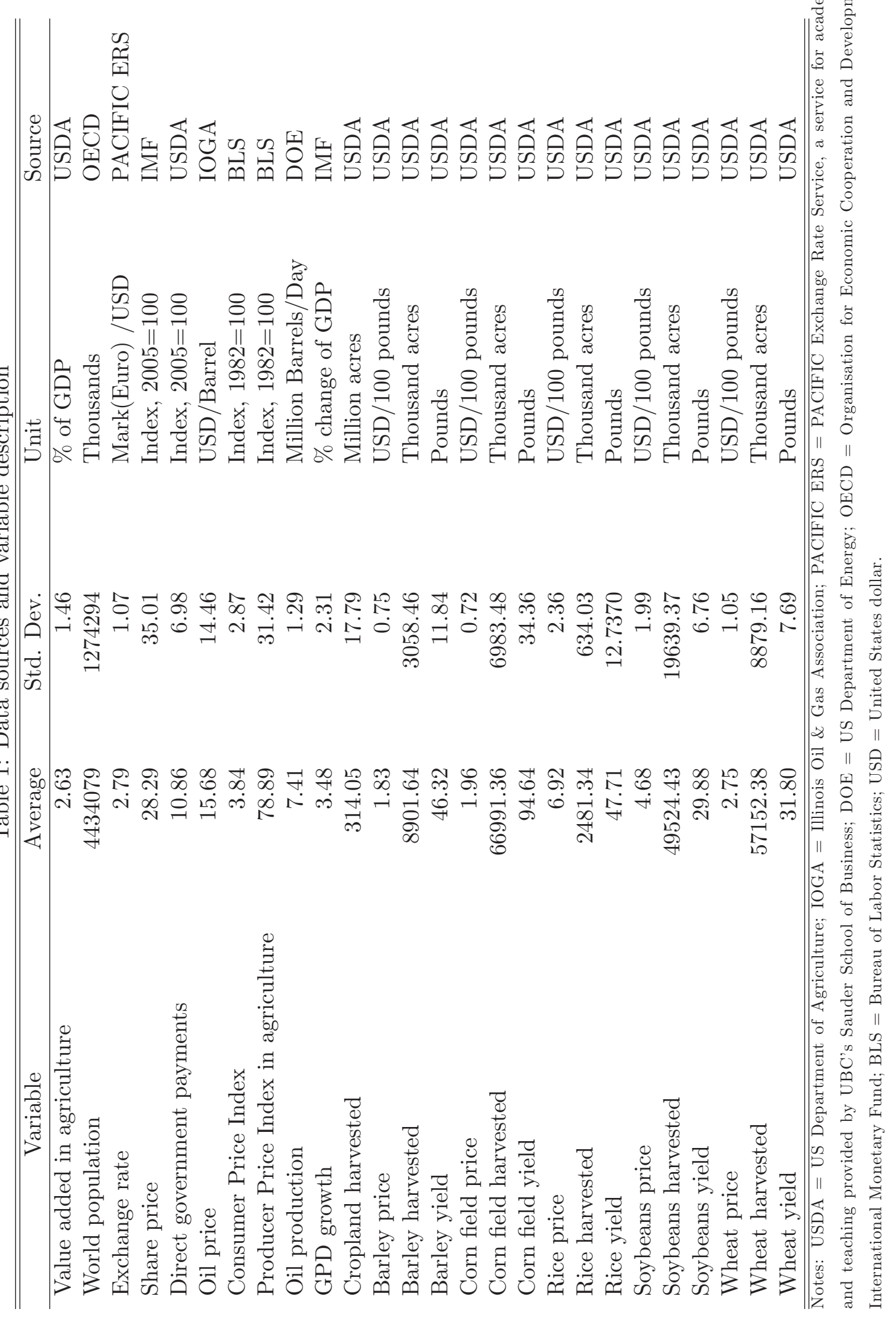




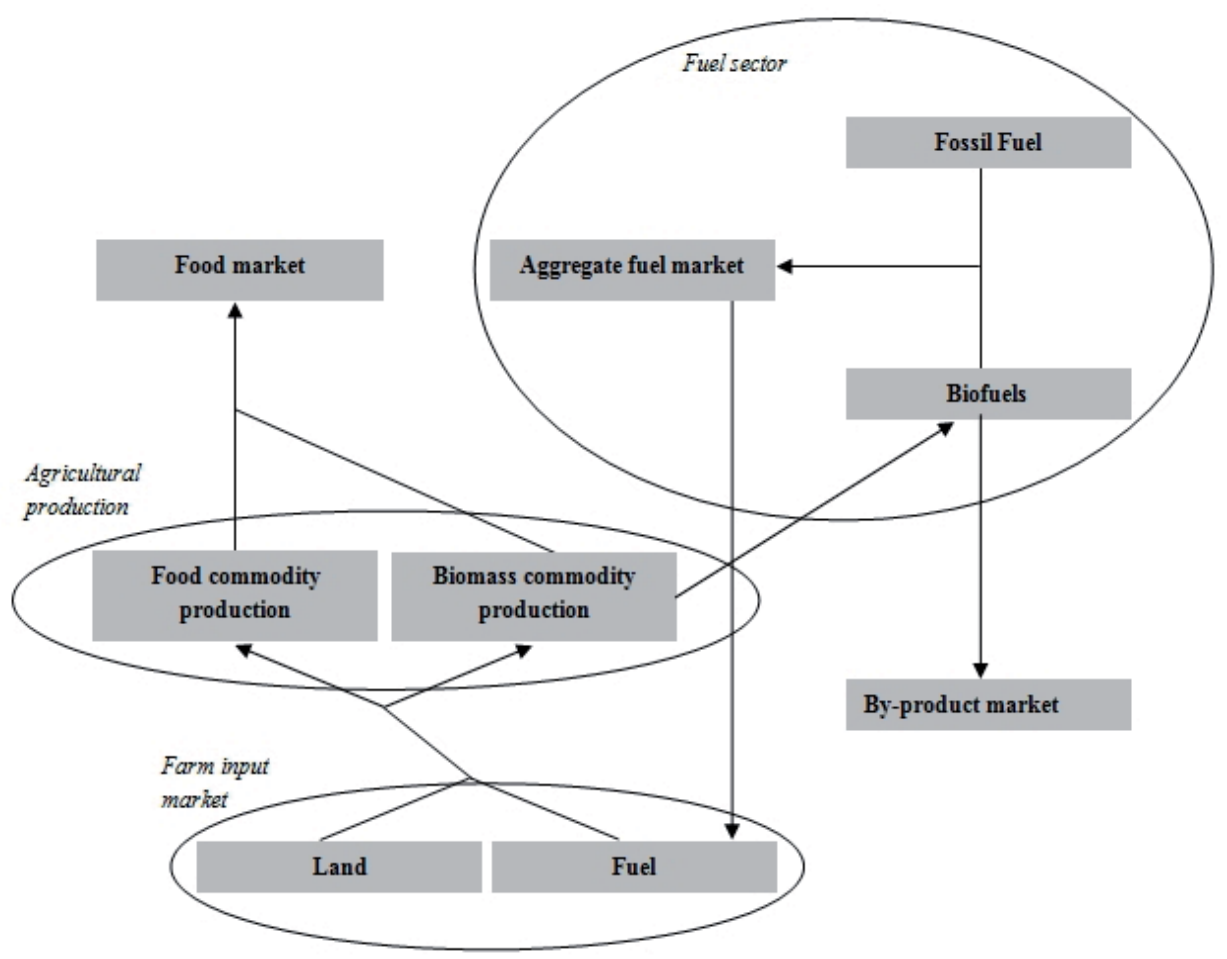

Figure 7: Structure of the model 
(a) Biomass Market

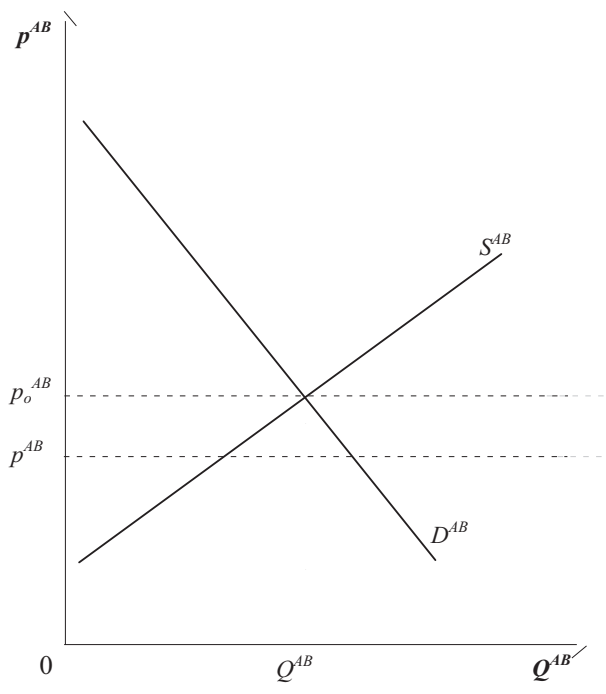

(b) Fuel Market

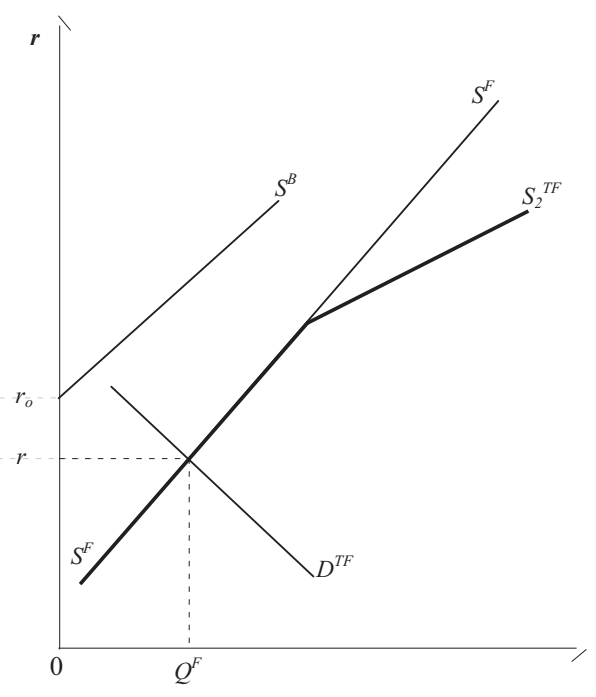

(d) Food commodity market

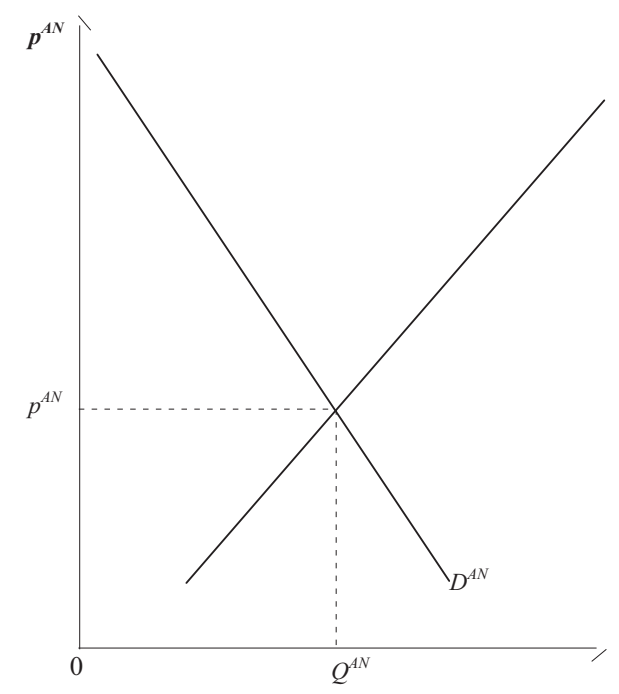

Figure 8: Biomass, fuel and food commodity markets 
Table 2: Estimated long-run land use elasticities

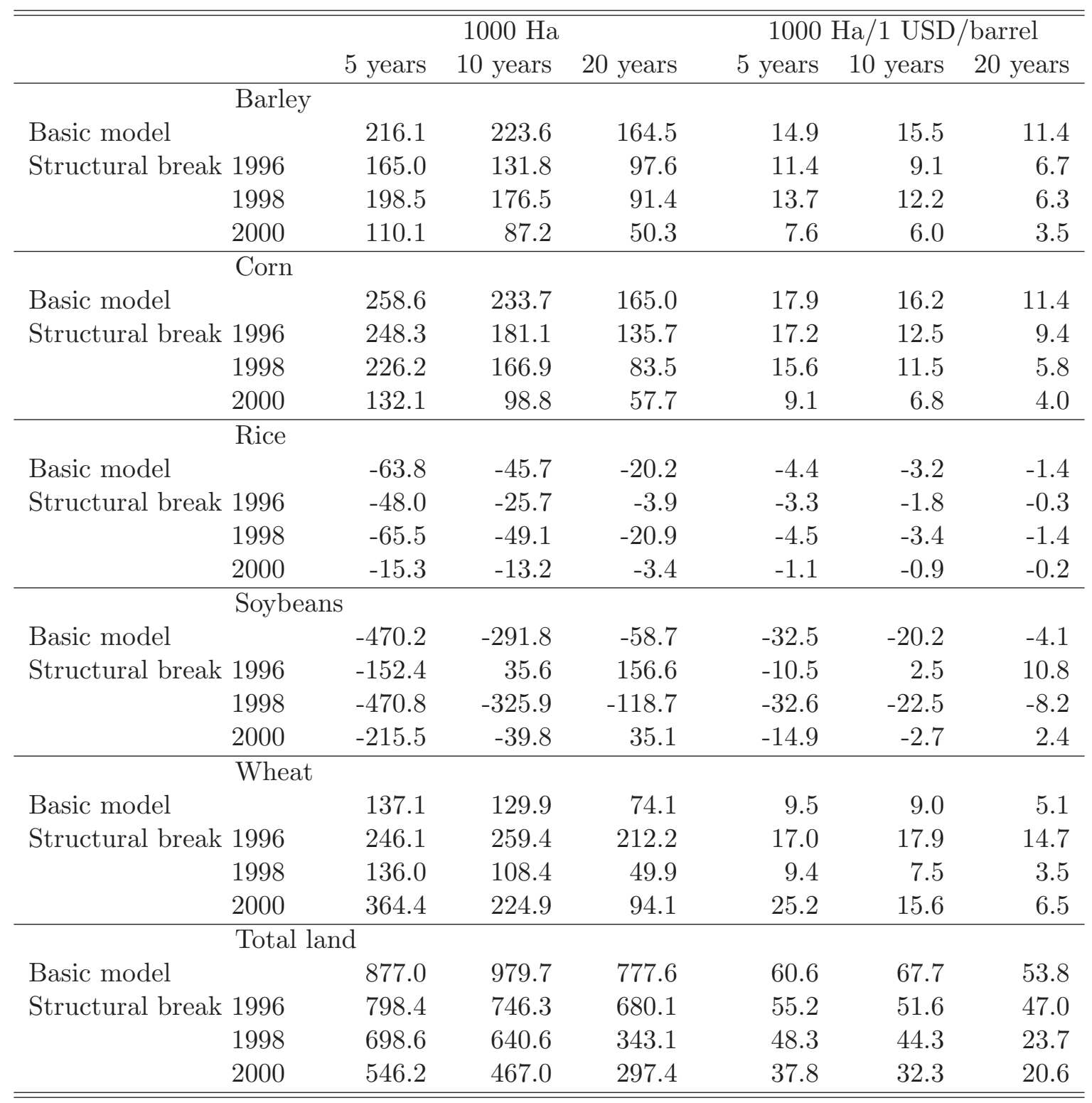

Source: Authors' estimations based on US data for 1950-2007. Notes: Land use change elasticities are calculated based on the impulse response analysis. 